\title{
EVALUATION OF DISINTEGRATION AND DISSOLUTION TEST OF METOCLOPRAMIDE ORALLY DISINTEGRATING TABLET USING MALTODEXTRINS FROM BANANA STARCH (MUSA PARADISIACA L) AS SUPERDISINTEGRANT
}

\author{
MINDA SARI LUBIS* \\ Department of Pharmaceutical Technology, University of Muslim Nusantara Al-Washliyah Medan, Indonesia. \\ Email: mindimindi@ymail.com
}

Received: 10 January 2018, Revised: 19 February 2018 and Accepted: 20 February 2018

\section{ABSTRACT}

Objective: The objective of this study was to know maltodextrin can be used as a superdisintegrant and to know the dissolution time and to know disintegration and dissolution test of metoclopramide orally disintegrating tablet (ODT) better than conventional metoclopramide tablets.

Methods: The methods used in this study include the formulation of banana starch, formulation of maltodextrin, and then maltodextrin formulated into ODT with metoclopramide drug model, and evaluated the disintegration and dissolution test of ODT metoclopramide.

Results: The results of the evaluation of 5 ODT formulas studied, showed ODT with maltodextrin 15\% (ODT 4) gave the fastest in vitro disintegration of $22.2 \mathrm{~s}$, the in vivo disintegration averaged between $55.38 \mathrm{~s}$ and $75.72 \mathrm{~s}$, and dissolution test results against ODT 4 and metoclopramide tablets (positive comparator) showed statistically significant differences $(\mathrm{p}<0.05)$.

Conclusion: Maltodextrin can be formulated superdisintegrant on metoclopramide ODT by giving disintegration, and dissolution was better than the conventional tablets.

Keywords: Maltodextrin, Superdisintegrant, Orally disintegrating tablet.

(c) 2018 The Authors. Published by Innovare Academic Sciences Pvt Ltd. This is an open access article under the CC BY license (http://creativecommons. org/licenses/by/4. 0/) DOI: http://dx.doi.org/10.22159/ajpcr.2018.v11s1.26609

\section{INTRODUCTION}

Maltodextrin is one of the starch derivatives known as safe food [1]. Maltodextrins are produced from a partial hydrolysis process by an $\alpha$-amylase enzyme having a dextrose equivalent (DE) value of $<20$. Maltodextrins have high solubility and are readily soluble in cold water, capable of forming films, low hygroscopicity, capable of dispersing auxiliaries, and capable of inhibiting crystallization and has a strong binding [2]. Maltodextrins are oligosaccharides belonging to prebiotics. Starches of this group provide more benefits in the food industry, even pharmaceuticals. In the pharmaceutical field, maltodextrin has also been used as a thin-film coating agent and as a drug carrier niosome [3].

Banana is one of the plants that contain the source of starch. However, not all types of bananas produce starch with good quality. The best result of starch is starch made from banana [4]. The banana has good physicochemical properties, so banana has great potential to be developed as food and other necessities, for example, as an additional material in the pharmaceutical field, either in the form of original starch or in the form of modified result.

Drug delivery systems are a means of strategy for product development and extending the product life cycle in the pharmaceutical market. To assist patients, several rapidly destroyed drug delivery systems have been developed [5]. One of them is an orally disintegrating tablet (ODT). According to the Food and Drugs Administration, USA, ODT is defined as a solid dosage form containing the active compound of the drug, which can be destroyed rapidly, usually in seconds, when placed on the tongue. The main criterion of ODT is rapidly destroyed in the oral cavity with the help of saliva in 15-60 s [6]. The desiccant (disintegrant/ superdisintegrant) is used to meet the criteria by which the tablet is destroyed at a set time limit.

Based on the nature and usefulness of maltodextrin described above and to improve the use of maltodextrin, the authors are interested in conducting research on the use of maltodextrin from banana ply starch as superdisintegrant in the ODT preparation with the metoclopramide drug model.

\section{METHODS}

\section{Research design}

The methods used in this study include the manufacture of banana starch and maltodextrin manufacture, then maltodextrin is formulated into ODT preparations. The ODT preparation will be evaluated for crushing time in vitro, in vivo, and dissolution.

\section{Materials}

The ingredients used in this study were raw bananas, distilled water, $\alpha$-amylase enzymes (LIPI Bogor), commercial maltodextrin (Qinhuangdao Lihua Starch Co., Ltd.), metoclopramide tablets (Soho), and pro quality chemicals analysis (E Merck, Germany), namely: Sodium sulfite, sodium hydroxide, hydrochloric acid, magnesium stearate, talc, and mannitol.

\section{Preparation of banana starch}

The raw banana peel is peeled, washed, cut into pieces, then weighed with a total weight of $500 \mathrm{~g}$, put in a blender and $500 \mathrm{ml}$ of Sodium Sulfite solution, turned on a blender for 2 min at low speed, then covered with a cloth, squeezed, then the dregs are added with distilled water, scraped, and squeezed again until the water is clear. The combined filtrate was allowed to stand for $12 \mathrm{~h}$, then discharged the solution and added distilled water, silenced again until the solution was clear. The solution was removed, and the resulting starch deposit was dried in an oven at $40^{\circ} \mathrm{C}$ for $48 \mathrm{~h}$, then dried starch, crushed inside the mortar, and sieved with no sieve 60 . The obtained banana starch is stored at room temperature in a sealed container [7].

\section{Preparation of maltodextrin}

$60 \mathrm{~g}$ of banana starch is suspended with distilled water until the volume is $300 \mathrm{ml}$. The resulting suspension regulated its $\mathrm{pH}$ to $5.5 \mathrm{using} \mathrm{pH}$ 
meter by adding $0.1 \mathrm{~N} \mathrm{NaOH}$. To the mixture was added $50 \mathrm{ml}$ of $\alpha$-amylase enzyme then incubated for $30 \mathrm{~min}$ at $60^{\circ} \mathrm{C}$. Subsequently, the mixture was cooled by immersing the container in cold water to a temperature of $30-40^{\circ} \mathrm{C}$, to stop enzyme activity by adding $\mathrm{HCl} 0.1 \mathrm{~N}$ to a $\mathrm{pH}$ of 3.5-4.5. After $30 \mathrm{~min}$, the obtained solution was neutralized with $0.1 \mathrm{~N} \mathrm{NaOH}$ to a pH of 7.0. The results obtained in the freeze dryer then determined DE. The obtained maltodextrin is stored at room temperature in a sealed container [8]

\section{Preparation of ODT Metoclopramide}

Tablets are made in direct print with $200 \mathrm{mg}$ tablet weight and $9 \mathrm{~mm}$ cross-section. Maltodextrin was used as a disintegrant with concentrations of $0 \%, 5 \%, 10 \%, 15 \%$, and $100 \%$ (ODT1-ODT5). Drugs used are metoclopramide $\mathrm{HCl}$.

The composition of ODT Metoclopramide can be seen in Table 1

Each material is weighed and then put into the mixture and mixed until homogeneous. The homogeneous mixture is then printed directly with the tablet press machine.

\section{Evaluation of destroyed time in vitro}

One tablet is inserted in each tube of the basket and used water temperature $37^{\circ} \pm 2^{\circ}$ as a medium, then tool run. The crushed time of the tablet is recorded that since the basket containing the tablet is raised down until the tablet is destroyed. Tablets declared destroyed if no part of the tablet left behind Dikasa [9]

\section{Evaluation of destroyed time in vivo}

This test uses six volunteers before the test runs, each volunteer is required to wake his mouth, then attach one ODT tablet on top of their tongue and leave the tablet completely destroyed. The time it takes for the tablet to crumble without chewing is calculated, after which the tablet is immediately spit out. Repeat 3 times for each volunteer. The endpoint for the crushed time of the mouth is the time when the tablet wrapped in the tongue becomes crushed (the tablet is not intact anymore)

\section{Evaluation of dissolution test}

In vitro, drug release studies were performed using a Type 2 (paddle) dissolution tool with a dissolution medium of $900 \mathrm{ml}$ of $37 \pm 0.5^{\circ} \mathrm{C}$ with a spin speed of $50 \mathrm{rpm}$ within $30 \mathrm{~min}$. At intervals of $1 \mathrm{~min}, 2.5 \mathrm{~min}$, $5 \mathrm{~min}, 10 \mathrm{~min}, 15 \mathrm{~min}, 20 \mathrm{~min}, 25 \mathrm{~min}$, and $30 \mathrm{~min}$, then $10 \mathrm{ml}$ of the trailer was taken. The cupping takes place in the same position that is between the surface medium of dissolution and the upper part of the paddle no $<1 \mathrm{~cm}$ from the container wall [10]. This sample solution is then measured uptake using an ultraviolet spectrophotometer at a wavelength of $272 \mathrm{~nm}$. Furthermore, the cumulative percentage of drug release is obtained. The dissolution test was performed on ODT and metoclopramide tablets.

Data obtained from drug release profiles from ODT and metoclopramide tablet preparations were compared in vitro. Data were compared using $\mathrm{t}$-test with significance $0.05(\mathrm{p}=0.05)$. Statistical analysis was performed using SPSS 16.0 program.

\section{RESULTS}

\section{Results of banana starch examination}

The source of starch used in this study is banana raw. The process of insulating starch is done using as many as $2000 \mathrm{~g}$ of raw banana. The yield of the isolation process is $875 \mathrm{~g} \mathrm{(43.75 \% )}$ of banana starch. This shows that the starch content in the raw banana fruit has not been hydrolyzed. The characterization of banana starch can be seen in Table 2.

\section{Result of maltodextrin examination}

In this study used banana kepok starch as a source of raw materials for the manufacture of maltodextrin. The maltodextrin hydrolysis process of the banana starch is enzymatically enriched as follows: $60 \mathrm{~g}$ banana
Table 1: Formulation of ODT metoclopramide

\begin{tabular}{|c|c|c|c|c|c|}
\hline \multirow[t]{2}{*}{ Materials (mg) } & \multicolumn{5}{|c|}{ Formulation code } \\
\hline & ODT1 & ODT2 & ODT3 & ODT4 & ODT5 \\
\hline Metoclopramide & 10 & 10 & 10 & 10 & 10 \\
\hline Maltodextrin & - & 10 & 20 & 30 & 182.5 \\
\hline $\begin{array}{l}\text { Magnesium } \\
\text { stearate }\end{array}$ & 5 & 5 & 5 & 5 & 5 \\
\hline Talc & 2.5 & 2.5 & 2.5 & 2.5 & 2.5 \\
\hline Mannitol & 182.5 & 172.5 & 162.5 & 152.5 & - \\
\hline Total & 200 & 200 & 200 & 200 & 200 \\
\hline
\end{tabular}

Metoclopramide=Drug, Maltodextrin=Disintegrant, Magnesium stearate=lubricant, Talc=Lubricant, Mannitol=Filler. ODT: Orally disintegrating tablet

Table 2: Result characterization banana strach

\begin{tabular}{ll}
\hline Examination & Result \\
\hline Microscopic & $\begin{array}{l}\text { Single items. Oval shape or round oval } \\
\text { grains. Hilus is a point on a narrow end with } \\
\text { a clear concentric lamella }\end{array}$ \\
Organoleptic & Smooth powder \\
Shape & White \\
Color & No smell \\
Smell & No taste \\
Taste & The white viscous solution is not \\
Identification & transparent \\
a. Suspension in & Dark blue, when heated the blue color \\
water with heating & disappears and reappears when cooled \\
b. Iodine test & Do not change the color of red litmus paper \\
& 4.7 \\
c. Litmus paper & $11.23 \%$ \\
d. pH meters & $0.29 \%$ \\
Water content & $4.3 \%$ \\
Ash content & $8.6 \%$ \\
Solubility &
\end{tabular}

starch is suspended with distilled water up to $300 \mathrm{ml}$, so the total weight of the suspense is $300 \mathrm{~g}$.

\section{Result of destroyed time in vitro}

In this study, the crushed time criterion of the ODT preparation is expected to be $<30 \mathrm{~s}$. To be able to meet the criteria of disintegration time required a disintegrant. Disintegrant is a material or combination of ingredients to expand and destroy the tablet after contact with water or disintegration medium so that the absorption of a nutritious substance works well. In this study used maltodextrin as a disintegrant. Use of maltodextrin as a good disintegrant is generally 5-15\%. Excessive use of maltodextrin will actually decrease the destruction time of tablets. The crushed time in vitro tablet meets the expected criteria except on ODT1 and ODT5. ODT1 gives a break time of $80.5 \mathrm{~s}$; this is due to the composition of the formula in ODT1 in the absence of maltodextrin as a disintegrant. The result of tablet to ODT1-ODT5 can be seen in Table 4.

Crusher added to facilitate rupture or destruction of tablets when in contact with liquids, may also serve to pull water into the tablet, inflate and cause the tablet to rupture [11]. While on ODT5 gives the destruction time of $83 \mathrm{~s}$. The high time destroyed tablets in ODT5 is due to the use of maltodextrins in large quantities (excessive). Known maltodextrins have the ability to add cohesion between the particles so that the density of the granules will be higher, causing the longer disintegration time.

Table 3 also shows that ODT4 has the fastest in vitro breakdown time of $22.2 \mathrm{~s}$, compared to ODT3 (27.5 s), ODT2 (36.5 s), ODT1 (80.5 s), and ODT5 $(83,8 \mathrm{~s})$. ODT4 is a formula using $15 \%$ maltodextrin as disintegrant and mannitol as filler. This ODT4 shows the fastest in vitro 
Table 3: Condition manufacture of maltodextrin from banana starch

\begin{tabular}{lllll}
\hline Temperature $\left({ }^{\circ} \mathrm{C}\right)$ & $\begin{array}{l}\text { Enzyme } \\
\text { volume }(\mathrm{ml})\end{array}$ & $\begin{array}{l}\text { Time } \\
\text { (menit) }\end{array}$ & $\begin{array}{l}\text { Fehling } \\
\text { test }\end{array}$ & DE \\
\hline 72 & 15 & 15 & - & - \\
72 & 30 & 15 & - & - \\
60 & 15 & 15 & - & - \\
60 & 15 & 30 & + & 5 \\
60 & 30 & 30 & + & 11 \\
60 & 50 & 30 & + & 17, \\
& & & & 18 \\
\hline
\end{tabular}

Table 4: Result of tablet to ODT1-ODT5

\begin{tabular}{ll}
\hline Formulation code & Time destroyed* in vitro (detik) \\
\hline ODT1 & $80.5 \pm 2.9313$ \\
ODT2 & $36.5 \pm 1.0393$ \\
ODT3 & $27.5 \pm 0.8830$ \\
ODT4 & $22.2 \pm 1.0756$ \\
ODT5 & $83.0 \pm 1.7895$ \\
Criteria & $<30$ detik \\
\hline
\end{tabular}

*6 repetition treatments. ODT: Orally disintegrating tablet

destroy time. Based on the above description, the researchers chose the ODT4 formula untu evaluated further.

\section{Result of destroyed time in vivo}

Destroyed time in vivo is the time it takes to break down in the mouth. The endpoint for time devastated in the mouth is the time when the tablets are placed on the tongue, crushed until there is no complete clump. The results of the destroyed in vivo ODT4 time test can be seen in Appendix 38 which shows that all the formula meets the expected criteria as ODT in this study since the in vivo crushed time of the tablet's average is about $55.38 \pm 0.296 \mathrm{~s}-75.72 \pm 1.5856 \mathrm{~s}$ $(<60 \mathrm{~s})$.

In the mouth, the fastest in vivo destroyed time was about 55.38 \pm 0.296 $\mathrm{s}$, indicated by the $5^{\text {th }}$ volunteer; this corresponds to the expected ODT criterion of $<60 \mathrm{~s}$. This indicates that the tablet will be destroyed when contact with saliva in the mouth. A low salivary amount (about $2 \mathrm{ml}$ ) in the mouth. Results in vivo degradation time longer than wetting time.

\section{Result of dissolution test}

The dissolution test was performed using a rowing method with a speed of $50 \mathrm{rpm}$, a distilled water medium, which within $30 \mathrm{~min}$ of dissolved metoclopramide was not $<75 \%$ of the amount indicated on the label

In this study expected dissolution criteria of ODT metoclopramide gave the release of an active ingredient not more than 30\% at min 1 and not $<85 \%$ at min 15 . Dissolution tests were performed on ODT4 and metoclopramide tablets. The cumulative average of the dissolution test results can be seen in Table 5 :

The average cumulative $\%$ graphic image of the dissolution test results of the ODT4 and metoclopramide tablets can be seen in Fig. 1.

From Table 5 and Fig. 1, it can be seen that cumulative percent dissolved in the $1^{\text {st }} \mathrm{min}, 15^{\text {th }} \mathrm{min}$, and $30^{\text {th }} \mathrm{min}$ for ODT4 $53.17 \%, 94.70 \%$, and $103.64 \%$ while for tablet metoclopramide of $12.40 \%, 46.37 \%$, and $81.69 \%$. Drug release from ODT4 does not meet the expected criteria, although ODT4 provides drug release about 2-4 times faster than metoclopramide tablets. This suggests that maltodextrin as a disintegrant may increase the rate of drug release. The rate of drug release is the stage that most determines the speed of drug bioavailability [8].
Table 5: Result of dissolution test average ODT4 metoclopramide

\begin{tabular}{llll}
\hline Tablet name & Time (min) & $\begin{array}{l}\text { \% cumulative } \\
\text { average }\end{array}$ & $\begin{array}{l}\text { Deviation } \\
\text { standard* }\end{array}$ \\
\hline ODT4 & 1 & 53.1722 & 6.2626 \\
& 2.5 & 57.6299 & 7.8990 \\
& 5 & 73.4161 & 10.589 \\
& 10 & 88.7379 & 5.5794 \\
& 15 & 94.6993 & 6.5228 \\
& 20 & 101.599 & 4.2240 \\
Metoclopramide tablet & 1 & 103.489 & 3.6289 \\
& 25 & 103.635 & 2.5148 \\
& 2.5 & 12.4042 & 0.6071 \\
& 5 & 17.9895 & 2.9031 \\
& 10 & 24.851 & 4.6533 \\
& 15 & 33.4791 & 6.2200 \\
& 20 & 46.3697 & 4.8675 \\
& 25 & 59.06 & 6.1405 \\
& 30 & 69.4786 & 6.7129 \\
& 81.6883 & 6.0193 \\
\hline
\end{tabular}

*6 repetition treatments. ODT: Orally disintegrating tablet

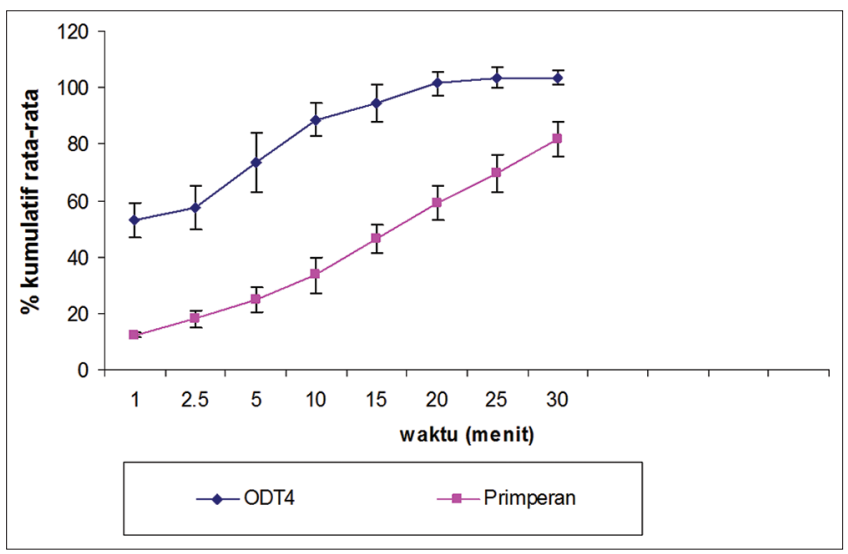

Fig. 1: The average cumulative cumulative graph of the dissolution test results of the orally desintegrating Tablet 4 and metoclopramide tablets in the distilled water distillation medium

\section{CONCLUSION}

Based on the observations made and the discussion can be concluded that maltodextrin derived from the process of hydrolysis of banana starch with the $\alpha$-amylase enzyme can be used as a superdisintegrant in the manufacture of ODT. Viewed from the crash time, and drug release profile that meets ODT criteria. The dissolution of ODTs is better than the dissolution of metoclopramide tablets because ODT4 provides faster drug release than metoclopramide tablets and shows statistically significant differences $(\mathrm{p}<0.05)$

\section{REFERENCES}

1. Blancard PH, Katz FR. Starch Hydrolysates. In: Stephen AM, editor. Food Polysaccharides and Their Application. New York: Marcel Dekker, Inc.; 1995. p. 121.

2. Roozen MJ, Hemminga MA, Walstra P. Molecular motion in glassy water malto- oligosaccharide (maltodexrtin) mixtures as studied by conventional and saturation-transfer spin-probe spectroscopy. Carbohydr Res 1991;215:229-37.

3. Li LC, Peck GE. The effect of moisture content on the compression properties of maltodextrins. J Pharm Pharmacol. 1990;42:272-5.

4. Luis A, Edith A, Laura S, Octavio P. Isolation and partial characterization of banana starch. J Agric Food Chem 1999;47:854-7.

5. Aurora J, Pathak V. Oral disintegrating technologies: Oral disintegrating dosage forms: An overview. Drug Deliv Technol 2005;5:50-4.

6. DeRoche CC, et al. Consumer Preference for Orally Disintegrating 
Tablets Over Conventional Forms of Medication: Evolving Methodology for Medication Intake in Dysphagia. San Francisco: Lecture Presented at the $12^{\text {th }}$ Annual Meeting of the Dysphagia Research Society; 2003

7. Kim Y, Wiesenborn D, Orr P, Grant L. Screening potato starch for novel properties using differential scanning calorimetry. J Food Sci 1995;60:1060-5

8. Blazek-Welsh AI, Rhodes DG. Maltodextrin-based proniosomes.
Pharm Sci 2001;3:1-8

9. Ditjen PO. Farmakope Indonesia. $3^{\text {rd }}$ ed. Jakarta: Ministry of Health Republic of Indonesia; 1979.

10. Ditjen PO. Farmakope Indonesia. $4^{\text {th }}$ ed. Jakarta: Ministry of Health Republic of Indonesia; 1995. p. 649.

11. Lachman L, Liebermann HA, Kanig JI. Theory and Practice of Pharmaceutical Industry. $3^{\text {rd }}$ ed. Jakarta: UI Press; 1994. p. 111, 142, 146-47, 339-57, 645, 652-3, 657-60. 